\title{
Xenon does not reduce opioid requirement for orthopedic surgery
}

\author{
[Le xénon ne réduit pas les besoins d'opiö̈des en chirurgie orthopédique]
}

Martin Luginbühl MD, * Steen Petersen-Felix PD DR MED, * Alex M. Zbinden, *

Thomas W. Schnider PD DR MED $\dagger$

Purpose: Is to test the hypothesis that $70 \%$ xenon has a relevant opioid sparing effect compared to a minimum alveolar concentration (MAC)-equivalent combination of $\mathrm{N}_{2} \mathrm{O}$ and desflurane.

Methods: In this randomized, controlled study of 30 patients undergoing major orthopedic surgery, we determined the plasma alfentanil concentration required to suppress response to skin incision in $50 \%$ of patients $\left(\mathrm{Cp}_{50}\right)$ anesthetized with xenon $(70 \%)$ or a combination of $\mathrm{N}_{2} \mathrm{O}(70 \%)$ and desflurane (2\%). A response was defined as movement, pressor response $>15 \mathrm{mmHg}$, heart rate $>90$ beats $\cdot \mathrm{min}^{-1}$, autonomic reactions or a combination of these. At skin incision, alfentanil was administered at a randomly selected target plasma concentration thereafter the concentration was increased or decreased according to the patient's response. After skin incision, desflurane was adjusted to maintain the bispectral index below 60 and prevent responsiveness in both groups.

Results: The $\mathrm{Cp}_{50}$ ( \pm standard error) of alfentanil was $83 \pm 48$ $\mathrm{ng} \cdot \mathrm{mL}^{-1}$ with xenon and $49 \pm 26 \mathrm{ng} \cdot \mathrm{mL}^{-1}$ with $\mathrm{N}_{2} \mathrm{O} /$ desflurane $(P$ $=0.45 \mathrm{I}$ ). During surgery five xenon and $15 \mathrm{~N}_{2} \mathrm{O} /$ desflurane patients were given desflurane at $1.0 \pm 0.5$ volume $\%$ and $2.5 \pm$ 0.7 volume $\%$. The total age adjusted MAC was $0.97 \pm 0.07$ and $0.94 \pm 0.07$ respectively $(P=0.217)$. The intraoperative plasma alfentanil concentrations were $95 \pm 80$ and $93 \pm 60 \mathrm{ng} \cdot \mathrm{mL}^{-1}$ respectively (mean $\pm \mathrm{SD} ; P=0.45 \mathrm{I}$ ). Patients given xenon were slightly more bradycardic, whereas blood pressure was similar.

Conclusion: Xenon compared to a MAC-equivalent combination of $\mathrm{N}_{2} \mathrm{O}$ and desflurane does not substantially reduce opioid requirement for orthopedic surgery. A small but clinically irrelevant difference cannot be excluded, however.
Objectif: Vérifier l'hypothèse voulant que le xénon à $70 \%$ permette de réduire significativement les opioïdes en comparaison d'une combinaison équivalente de concentration alvéolaire minimale (CAM) de $\mathrm{N}_{2} \mathrm{O}$ et de desflurane.

Méthode : L'étude randomisée et contrôlée comptait 30 patients devant subir une intervention orthopédique majeure. La concentration plasmatique d'alfentanil nécessaire pour supprimer la réaction à une incision cutanée chez $50 \%$ des patients (Cp50) sous anesthésie au xénon (70\%) ou une combinaison de $\mathrm{N}_{2} \mathrm{O}(70 \%)$ et de desflurane (2\%) a été déterminée. Une réaction était un mouvement, une réponse vasopressive $>15 \mathrm{mmHg}$, une fréquence cardiaque $>90$ battements: $\mathrm{min}^{-1}$, des réactions autonomes ou une des réactions combinées. Lors de l'incision cutanée, l'alfentanil était administré selon une concentration plasmatique cible choisie aléatoirement, et la concentration augmentée ou diminuée selon la réaction du patient. Après l'incision, le desflurane était ajusté pour maintenir l'index bispectral en bas de 60 et éliminer les réactions chez tous les patients.

Résultats : La Cp50 ( \pm erreur type) de l'alfentanil a été de $83 \pm$ $48 \mathrm{ng} \cdot \mathrm{mL}^{-1}$ avec le xénon et de $49 \pm 26 \mathrm{ng} \cdot \mathrm{mL}^{-1}$ avec $\mathrm{N}_{2} \mathrm{O} /$ desflurane $(P=0,451)$. Pendant l'opération, cinq patients sous xénon et 15 sous $\mathrm{N}_{2} \mathrm{O} /$ desflurane ont reçu du desflurane à $1,0 \pm 0,5$ volume $\%$ et $2,5 \pm 0,7$ volume \%. L'ajustement total de la CAM en fonction de l'âge a été de 0,97 $\pm 0,07$ et de 0,94 $\pm 0,07$ respectivement $(P=$ $0,217)$. les concentrations plasmatiques d'alfentanil ont été de $95 \pm$ 80 et de $93 \pm 60 \mathrm{ng} \cdot \mathrm{mL}^{-1}$ respectivement (moyenne \pm écart type ; $P=0,45$ I). Les patients qui ont reçu du xénon ont présenté un peu plus de bradycardie, mais la tension artérielle était similaire entre les groupes.

Conclusion : Le xénon, comparé à une CAM d'une combinaison équivalente de $\mathrm{N}_{2} \mathrm{O}$ et de desflurane, ne réduit pas significativement les besoins d'opiö̈des en orthopédie. On ne peut toutefois exclure une petite différence, mais cliniquement non significative.

From the Department of Anesthesiology, ${ }^{*}$ University Hospital of Bern, Bern; and the Department of Anesthesia, $†$ Kantonsspital St. Gallen, St. Gallen, Switzerland.

Address correspondence to: Dr. Martin Luginbühl, Department of Anesthesiology, University Hospital, CH-3010 Bern, Switzerland. Phone: +41-31-632-27-19; Fax: +41-31-632-05-54; E-mail: martin.luginbuehl@dkf.unibe.ch

Funded by the Department of Anesthesiology, University Hospital of Bern, Switzerland. Messer Griesheim GmbH, Krefeld, Germany, provided the xenon gas. Received from the Department of Anesthesiology, University Hospital of Bern, Switzerland.

Reprints will not be available from the authors.

Accepted for publication June 11, 2004.

Revision accepted September 13, 2004. 
M ORE than ten years ago Lachmann and co-workers detected a fivefold reduction of the fentanyl requirement for general surgery in patients anesthetized with $70 \%$ xenon compared to those anesthetized with $70 \%$ nitrous oxide $\left(\mathrm{N}_{2} \mathrm{O}\right)$ in oxygen. ${ }^{1}$ These results triggered a number of subsequent studies documenting the fast induction and emergence kinetics $^{2}$ and the cardiovascular stability of xenon. ${ }^{3,4}$ Xenon was also suggested as a potential alternative to $\mathrm{N}_{2} \mathrm{O}$ because it is not teratogenic. ${ }^{5}$ A recent randomized, controlled, multicentre study showed that anesthesia with xenon is safe and provides a more rapid recovery than isoflurane with $\mathrm{N}_{2} \mathrm{O} .{ }^{6}$

Although it is not surprising that the patients in the study by Lachmann and co-workers ${ }^{1}$ receiving one minimum alveolar concentration (MAC) of xenon required less fentanyl than the patients receiving 0.7 MAC of $\mathrm{N}_{2} \mathrm{O}$, the difference was far greater than expected from the difference in MAC. Because of its weak hypnotic effect $\mathrm{N}_{2} \mathrm{O}$ (with a MAC-awake of $\left.63 \%\right)^{7}$ must be supplemented by a potent volatile or $i v$ anesthetics to prevent awareness. ${ }^{8}$ The insufficient hypnosis of the $\mathrm{N}_{2} \mathrm{O}$ patients might, therefore, have biased Lachmann's study. We defined a control group where a sufficient depth of hypnosis would be ascertained by adding small concentrations of desflurane to $\mathrm{N}_{2} \mathrm{O}$. Adding $2.8 \mathrm{vol}-$ ume $\%$ of desflurane to $60 \% \mathrm{~N}_{2} \mathrm{O}$ corresponds to 1 MAC in middle-aged subjects. ${ }^{9}$ Assuming the two agents are additive, we considered $70 \% \mathrm{~N}_{2} \mathrm{O}$ plus 2 volume $\%$ desflurane as MAC-equivalent to $70 \%$ xenon. ${ }^{10}$ Because the MAC-awake of xenon is $33 \%,{ }^{7}$ we considered $70 \%$ xenon sufficiently hypnotic.

Given the large opioid sparing effect of xenon reported by Lachmann and co-workers ${ }^{1}$ we hypothesized that opioid requirements would be lower in xenon anesthetized patients even if control patients were given a MAC-equivalent combination of $\mathrm{N}_{2} \mathrm{O}$ /desflurane. We determined the alfentanil plasma concentration required to suppress the response to skin incision in $50 \%$ of patients $\left(\mathrm{Cp}_{50}\right)$ and the median alfentanil concentration necessary to suppress response to intraoperative surgical stimulation in patients anesthetized with $70 \%$ xenon or $\mathrm{N}_{2} \mathrm{O}$ supplemented with desflurane to maintain the bispectral index (BIS) level below 60 and to prevent responsiveness.

\section{Methods}

With approval of the local Ethical Committee and written informed consent, we recruited 30 ASA physical status I and II patients scheduled for elective orthopedic surgery. Patients were stratified ${ }^{11}$ according to age and type of surgery and randomly assigned to either xenon or $\mathrm{N}_{2} \mathrm{O}$ plus desflurane $\left(\mathrm{N}_{2} \mathrm{O} /\right.$ desflurane) anesthesia. Patients with diabetes mellitus; any relevant renal, liver, heart (including arterial hypertension), neurological, or psychiatric disease; a regular alcohol consumption of more than $20 \mathrm{~g}$ per day, ${ }^{12}$ drug abuse; or taking sedatives or long acting analgesic drugs were excluded. Additional details on the methods are available as Additional Material at www.cja-jca.org.

\section{Study plan}

Thirty minutes after premedication with $7.5 \mathrm{mg}$ midazolam po the patients were monitored with a Datex AS3 monitor and an Aspect Al000 BIS monitor (BIS version 3.2, Aspect Medical Systems, Inc., Newton, MA, USA). Anesthesia was induced with $2.5 \mathrm{mg} \cdot \mathrm{kg}^{-1}$ propofol, $1 \mu \mathrm{gg} \cdot \mathrm{kg}^{-1}$ remifentanil, and $0.1 \mathrm{mg} \cdot \mathrm{kg}^{-1}$ vecuronium to facilitate tracheal intubation. After induction, desflurane was administered at 3 volume \% and an arterial catheter was inserted into the radial artery of the non-dominant arm. A computer-controlled infusion of alfentanil was started at a randomly selected alfentanil target plasma concentration between 5 and $400 \mathrm{ng} \cdot \mathrm{mL}^{-1}$ (Stanpump program, pharmacokinetic parameters for alfentanil by Raemer et al. ${ }^{13}$ software freely available from S.L. Shafer, M.D., Palo Alto, CA, USA). The study gas (either $70 \% \mathrm{~N}_{2} \mathrm{O}$ or xenon) was then started (at least $15 \mathrm{~min}$ before $\mathrm{Cp}_{50}$ ) and desflurane was eliminated by use of a charcoal filter in the xenon group whereas it was reduced to 2 volume $\%$ in the $\mathrm{N}_{2} \mathrm{O}$ group. The maximal systolic blood pressure, heart rate, and any motor reaction within five minutes of skin incision were recorded. During surgery the xenon and $\mathrm{N}_{2} \mathrm{O}$ concentrations were kept constant at 70 volume $\%$ whereas the target plasma alfentanil concentration was increased by 25 to $50 \mathrm{ng} \cdot \mathrm{mL}^{-1}$ if the patient showed any response to incision as defined below. Conversely alfentanil was decreased by $25 \mathrm{ng} \cdot \mathrm{mL}^{-1}$ if the patient did not show any response to the surgical stimulation during the last $20 \mathrm{~min}$. The maximal target alfentanil concentration allowed was $500 \mathrm{ng} \cdot \mathrm{mL}^{-1}$. The patient's responsiveness to verbal command was checked every $20 \mathrm{~min}$ (isolated forearm technique). To prevent awareness and recall desflurane was adjusted in steps of 0.5 volume $\%$ in order to maintain the BIS below 60 and to prevent responsiveness. Desflurane was therefore allowed also in the xenon group as a rescue drug, if the patient was responsive or if the BIS increased above 60 for longer than four minutes. ${ }^{14}$

A response to skin incision or to intraoperative surgical stimulation was defined as a motor response, a blood pressure increase of more than $15 \mathrm{mmHg}$ above 
baseline, a heart rate increase above 90 beats. $\mathrm{min}^{-1}$ in the absence of hypovolemia, an autonomic response (such as tearing, sweating, or flushing) or a combination of these..$^{15}$ Baseline systolic blood pressure was defined as the average of measurements taken on the ward the day before surgery and in the operating room before induction.

All the data from the Datex AS3 monitor, the Aspect A1000 and a Dräger thermal conductivity sensor measuring the xenon concentration ${ }^{16}$ were recorded on a computer disk.

At baseline, immediately before and at five minutes after skin incision, and before and two to five minutes after each change of the target alfentanil concentration during surgery, an arterial blood sample was withdrawn for determination of the alfentanil plasma concentration. Blood samples for alfentanil measurement were immediately centrifuged at $3500 \mathrm{~g}$ for $30 \mathrm{~min}$ and the plasma stored at $-26^{\circ} \mathrm{C}$. Alfentanil plasma concentration was measured by gas chromatography mass spectrometry. ${ }^{17}$

On the second day after surgery a blinded investigator interviewed the patients for signs of explicit recall.

\section{Data analysis and statistics}

The alfentanil concentration to suppress patient response to skin incision was computed by logistic regression for the two study groups using NONMEM software (Sheiner LB, Beal SL: NONMEM user's Guide 1994, University of California San Francisco, CA, USA). For the intraoperative period the median of the plasma alfentanil concentrations measured between skin incision and closure and the median alfentanil infusion rate was determined.
According to Ausems et al. ${ }^{15}$ the $\mathrm{CP}_{50} \pm$ standard error (SE) of alfentanil to suppress response to $\mathrm{Cp}_{50}$ is $279(20) \mathrm{ng} \cdot \mathrm{mL}^{-1}(n=37)$ in a mixed population and to suppress an intraoperative response in breast surgery $270 \pm 63 \mathrm{ng} \cdot \mathrm{mL}^{-1}$ in patients anesthetized with $\mathrm{N}_{2} \mathrm{O}$ in oxygen without potent volatile anesthetics. With 15 subjects per group, we expected to detect a difference of $50 \mathrm{ng} \cdot \mathrm{mL}^{-1}$ between groups with a power of $>0.80$ (one tailed $\mathrm{t}$ test).

The number of blood pressure recordings greater than $20 \%$ or below $20 \%$ of baseline, the number of heart rate recordings above $90 \mathrm{~min}^{-1}$ or below $20 \%$ of baseline and the number of episodes with BIS $>60$ for longer than four minutes were determined for each subject. ${ }^{18}$

Data were compared with a Student's t test or a Wilcoxon rank test as appropriate. Results are presented as means \pm SDs or number of patients, unless otherwise noted. $P<0.05$ was considered significant.

\section{Results}

The characteristics of the two study groups were similar (Table I).

\section{Response to skin incision}

Two patients in each group were excluded from the analysis because the desflurane concentration accidentally differed more than $20 \%$ from the target value. The train-of-four count at $\mathrm{Cp}_{50}$ was four twitches in every subject. The $\mathrm{Cp}_{50}$ for alfentanil was $83 \pm 48$ $\mathrm{ng} \cdot \mathrm{mL}^{-1}$ in the xenon group and $48 \pm 25 \mathrm{ng} \cdot \mathrm{mL}^{-1}$ in the $\mathrm{N}_{2} \mathrm{O}$ /desflurane group (parameter estimate $\pm \mathrm{SE}$, $P=0.451 ;$ Figure 1$)$.

\section{Response during surgery}

All 15 patients of each group were included in the analysis. The median plasma alfentanil concentration

TABLE I Characteristics of the study population

\begin{tabular}{llll}
\hline & Xenon & $N_{2}$ O/desflurane & P value \\
\hline Men/women & $7 / 8$ & $9 / 6$ & 0.49 \\
Age; yr & $32 \pm 6$ & $33 \pm 11$ & 0.60 \\
Weight; kg & $69 \pm 14$ & $72 \pm 16$ & 0.53 \\
Height; cm & $172 \pm 6$ & $172 \pm 12$ & 0.62 \\
BMI* & $23 \pm 4$ & $24 \pm 4$ & 0.35 \\
ASA status (I/II) & $14 / 1$ & $12 / 3$ & 0.59 \\
Baseline systolic pressure; mmHg & $124 \pm 13$ & $121 \pm 11$ & 0.54 \\
Type of surgery & & & 0.70 \\
$\quad$ Hip dislocation & 11 & 9 & 1.0 \\
$\quad$ Periacetabular osteotomy & 3 & 4 & 1.0 \\
Luration back surgery & 1 & 2 & 0.42 \\
\hline
\end{tabular}

Data presented as mean $\pm \mathrm{SD}$ or number of patients. $\mathrm{N}_{2} \mathrm{O}=$ nitrous oxide; ${ }^{*} \mathrm{BMI}=$ body mass index. 


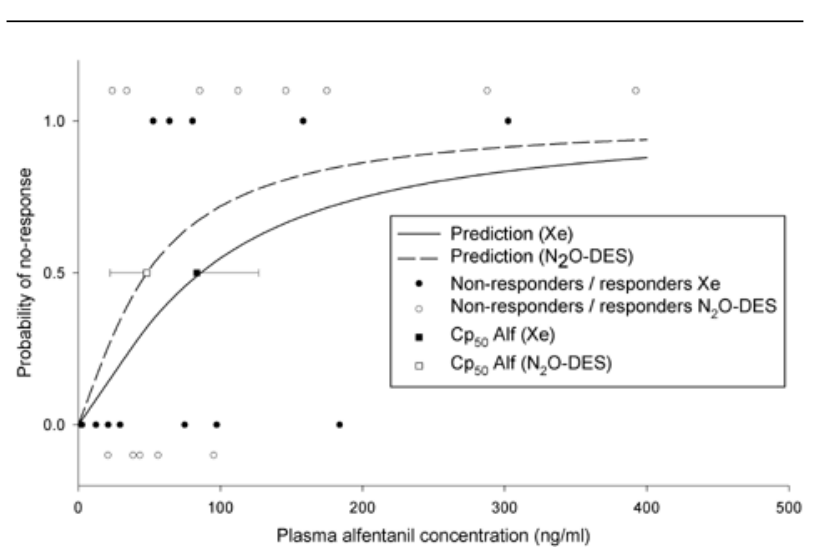

FIGURE 1 The predicted probability of no-response to skin incision $\left(\mathrm{Cp}_{50}\right)$ is plotted in relation to the measured plasma alfentanil concentration. Responders and non-responders of the xenon group are represented by filled circles and those of the nitrous oxide $\left(\mathrm{N}_{2} \mathrm{O}\right)$-desflurane group by open circles. The filled and open squares represent the $\mathrm{Cp}_{50}$ of alfentanil in the xenon and the $\mathrm{N}_{2} \mathrm{O} /$ desflurane group respectively (error bars $=$ standard error of the estimate).

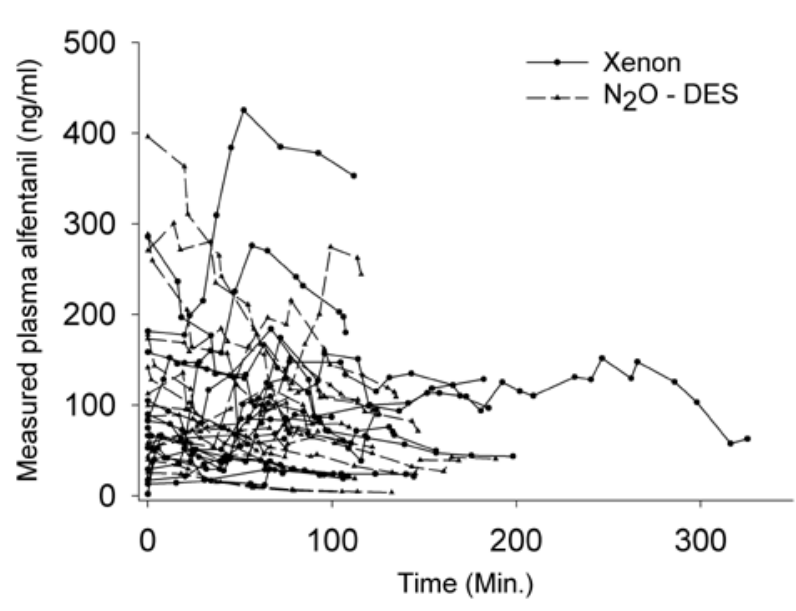

FIGURE 2 The measured plasma alfentanil concentrations between skin incision and closure are plotted for each subject. Solid lines with filled circles $=$ xenon patients, dashed lines with triangles $=$ nitrous oxide $\left(\mathrm{N}_{2} \mathrm{O}\right) /$ desflurane patients.

during surgery and the median alfentanil infusion rate to prevent intraoperative response was similar in the two groups (Table II). Five of 15 patients were given desflurane $(1.0 \pm 0.4$ volume $\%)$ in addition to xenon because of a sustained BIS increase $>60$ (four sub- jects) and uncontrollable blood pressure increase despite $500 \mathrm{ng} \cdot \mathrm{mL}^{-1}$ of alfentanil (one subject). In these patients the mean (SD) BIS level was $46(8)$ and the median alfentanil concentration was 111 (127) $\mathrm{ng} \cdot \mathrm{mL}^{-1}$. In xenon patients without desflurane the mean (SD) BIS level was $36(8)$ and the median alfentanil concentration was $86(49) \mathrm{ng} \cdot \mathrm{mL}^{-1}(P=0.075$ for BIS, $P=0.58$ for alfentanil). In the patients undergoing hip arthrotomy with surgical dislocation of the hip $^{19}$ the median alfentanil concentration during surgery was $100(39) \mathrm{ng} \cdot \mathrm{mL}^{-1}$ in the $\mathrm{N}_{2} \mathrm{O} /$ desflurane and $96(92) \mathrm{ng} \cdot \mathrm{mL}^{-1}$ in the xenon group $(P=0.92)$. Excluding the three xenon patients of this subgroup who were given desflurane, the median alfentanil concentration during surgery was $82(54) \mathrm{ng} \cdot \mathrm{mL}^{-1}(P=$ 0.43 compared to the $\mathrm{N}_{2} \mathrm{O} /$ desflurane patients).

No patient responded to verbal command during surgery. One patient in the $\mathrm{N}_{2} \mathrm{O}$ /desflurane group experienced awareness with recall during tracheal intubation because of a failure of desflurane supply before administration of the study gas. ${ }^{20}$

\section{Discussion}

In a previous study xenon, compared to $\mathrm{N}_{2} \mathrm{O}$, was associated with a reduction of fentanyl requirement by far exceeding the difference in MAC of the two gases. ${ }^{1}$ In contrast, our data do not show a relevant reduction of alfentanil requirements to suppress hemodynamic, autonomic or motor responses to $\mathrm{Cp}_{50}$ in xenon patients compared to those receiving a MAC-equivalent combination of $\mathrm{N}_{2} \mathrm{O}$ and desflurane. There was no difference in the alfentanil infusion rate and the mean measured alfentanil concentration during surgery even though the BIS level was lower in the xenon patients. The anesthetic regimens provided similar hemodynamic stability except for a higher incidence of bradycardia in the xenon group and a lower arterial pressure in the $\mathrm{N}_{2} \mathrm{O}$ /desflurane group. Xenon as the main anesthetic does not have an opioid sparing effect compared to a MAC-equivalent combination of $\mathrm{N}_{2} \mathrm{O}$ and desflurane.

Suppression of motor response to skin incision (MAC) has been the gold standard to measure the potency of anesthetics. It reflects mainly a spinal reflex independent of the anesthetic drug concentration in the brain, however. ${ }^{21}$ This is illustrated by the fact that the BIS did not predict movement response to insertion of a laryngeal mask. ${ }^{22}$ It is therefore not surprising that the BIS levels in the two study groups were different even though the post hoc calculation of ageadjusted total MAC was similar. If xenon had a true opioid-sparing effect, the alfentanil concentrations to suppress response to painful surgical stimulation 
TABLE II Hemodynamic responses, anesthetic gas concentrations and BIS level

\begin{tabular}{|c|c|c|c|}
\hline & Xenon & $\mathrm{N}_{2} \mathrm{O} /$ desflurane & P value \\
\hline Desflurane at skin incision (vol \%) & $0.10 \pm 0.09$ & $1.9 \pm 0.1$ & $<0.001$ \\
\hline BIS reading at skin incision & $34 \pm 10$ & $55 \pm 11$ & $<0.001$ \\
\hline Gas concentration (vol \%) & $70.7 \pm 1.3$ & $70.1 \pm 0.6$ & 0.101 \\
\hline Desflurane during surgery (vol \%)* & $1.0 \pm 0.4$ & $2.5 \pm 0.7$ & 0.002 \\
\hline MAC during surgery & $0.97(0.06)$ & $0.94(0.07)$ & 0.22 \\
\hline BIS reading during surgery & $40 \pm 10$ & $54 \pm 4$ & $<0.001$ \\
\hline Median alfentanil plasma conc. $\left(\mathrm{ng} \cdot \mathrm{mL}^{-1}\right) \ddagger$ & $95 \pm 80$ & $93 \pm 60$ & 0.95 \\
\hline Median alfentanil rate $\left(\mu \mathrm{g} \cdot \mathrm{kg}^{-1} \cdot \mathrm{min}^{-1}\right) \ddagger$ & $0.47(0.30-0.63)$ & $0.38(0.36-0.55)$ & 0.455 \\
\hline SAP; mmHgf & $128 \pm 12$ & $114 \pm 10$ & 0.002 \\
\hline SAP > upper limit $(\%) \ddagger \subseteq$ & $10.4(3-13.5)$ & $0.3(0-8)$ & 0.005 \\
\hline SAP $<$ lower limit $(\%) \ddagger \mathbb{I}$ & $4.6(4.1-6.1)$ & $4.4(3.9-26.2)$ & 0.772 \\
\hline HR; beats. $\min ^{-1} \ddagger$ & $54 \pm 6$ & $59 \pm 9$ & 0.117 \\
\hline HR > upper limit $(\%) \ddagger$ & $0(0-0.2)$ & $0(0-0.5)$ & 0.868 \\
\hline $\mathrm{HR}<$ lower limit $(\%) \ddagger \mathbb{I}$ & $93(66-99)$ & $51(15-92)$ & 0.031 \\
\hline
\end{tabular}

Data presented as mean \pm SD or medians (inter-quartile range) as appropriate. ${ }^{*}$ Calculated from the subjects given desflurane: five in the xenon group, 15 in the $\mathrm{N}_{2} \mathrm{O}$ /desflurane group; †Age-adjusted total MAC (study gas + desflurane); $\ddagger$ During surgery; $\$$ Systolic pressure upper limit $=15 \mathrm{mmHg}$ above baseline; $\mathfrak{\Phi}$ Lower limit $=20 \%$ lower than baseline; Heart rate upper limit $=90 \mathrm{beats} \cdot \mathrm{min}^{-1}$. BIS $=\mathrm{bispec}-$ tral index; $\mathrm{N}_{2} \mathrm{O}=$ nitrous oxide; $\mathrm{MAC}=$ minimum alveolar concentration; $\mathrm{SAP}=$ systolic arterial pressure; $\mathrm{HR}=$ heart rate.

would have been smaller even at a MAC-equivalent concentration. The difference in BIS level can be explained by the weak sedative effect of $\mathrm{N}_{2} \mathrm{O}$, which does not affect BIS. ${ }^{23}$ The BIS is a validated tool to measure depth of sedation with various $i v$ and inhalation anesthetics; among them $\mathrm{N}_{2} \mathrm{O}$ plus desflurane ${ }^{24}$ but not xenon. The BIS did not predict responsiveness to verbal command at emergence of xenon anesthesia. ${ }^{25}$ The deeper BIS levels in the xenon patients are therefore difficult to interpret and may not necessarily indicate a deeper hypnosis. Whatever the lower BIS levels mean, hemodynamic response and alfentanil requirements were not affected. Because of this uncertainty, desflurane was administered in four xenon patients because of a persistent BIS increase. Also, in these patients, alfentanil requirements were similar to those not given desflurane.

A xenon MAC of $71 \%{ }^{26}$ was the basis for the potency calculations for our study; however, in a recent study a MAC of $63 \%$ was reported for xenon. ${ }^{27}$ The $70 \%$ xenon we used did not only produce significantly lower BIS levels, but might even have been more potent than the combination of $70 \% \mathrm{~N}_{2} \mathrm{O}$ and $2 \%$ desflurane. Although this would suggest that the xenon patients would require less alfentanil they did not. Assuming a potency ratio of 1:70 between alfentanil and fentanyl, ${ }^{28}$ the plasma alfentanil concentration to prevent response to skin incision in our study $(83$ $\mathrm{ng} \cdot \mathrm{mL}^{-1}$ in the xenon and $49 \mathrm{ng} \cdot \mathrm{mL}^{-1}$ in the $\mathrm{N}_{2} \mathrm{O}$ /desflurane group) was in the same range as the value reported for fentanyl $\left(0.94 \mathrm{ng} \cdot \mathrm{mL}^{-1}\right) .{ }^{29}$
The limitation of our primary sample size calculation was that it had to be based on data from a study with a somewhat different design (e.g., $\mathrm{N}_{2} \mathrm{O}$ without volatile anesthetics). Compared to previous studies on alfentanil requirements to suppress motor and hemodynamic response to $C \mathrm{p}_{50}$ or intraoperative surgical stimuli ${ }^{15,30}$ we observed substantially greater standard deviations of our $\mathrm{Cp}_{50}$ values. A post hoc power analysis revealed that 15 subjects per group would allow detecting a difference between groups greater than $125 \mathrm{ng} \cdot \mathrm{mL}^{-1}$ for $\mathrm{Cp}_{50}$ and greater than $80 \mathrm{ng} \cdot \mathrm{mL}^{-1}$ for intraoperative alfentanil requirements with a power greater than 0.8 . Our $\mathrm{Cp}_{50}$ of alfentanil were below $100 \mathrm{ng} \cdot \mathrm{mL}^{-1}$ in both groups and thus far below the $\mathrm{Cp}_{50}$ for naloxone requirement of 223 (13) $\mathrm{ng} \cdot \mathrm{mL}^{-1}$ reported by Ausems et al. ${ }^{15}$ In order to reach sufficient power to detect a difference of $50 \mathrm{ng} \cdot \mathrm{mL}^{-1}$ as many as 150 patients per group would have been necessary. Due to the small sample size we therefore might have missed a small opioid sparing effect of xenon but we can exclude a substantial difference as reported by Lachmann and co-workers. ${ }^{15}$ In view of the high cost of this inhalation anesthetic a small difference would not be clinically relevant, however.

Using a stratified randomization protocol, the type of surgery was well balanced between the two groups (Table I). In the subgroup analysis of patients undergoing surgical dislocation of the hip ( 11 in the xenon and nine in the $\mathrm{N}_{2} \mathrm{O} /$ desflurane group) alfentanil requirements were not significantly different, even when the three xenon patients who were given desflu- 
rane are excluded. Even highly standardized conditions (one standardized operation) did not allow to detect a clinically relevant and statistically significant opioid sparing effect of xenon.

The definition of a response was previously used by Ausems and co-workers ${ }^{15}$ and is closest to clinical practice, where motor response, hemodynamic response or autonomic signs of inadequate anesthesia are also considered together for dosing anesthetic drugs.

Because of the uncertainty of the BIS as a measure of hypnotic depth during xenon anesthesia ${ }^{15}$ we additionally used the isolated forearm technique for clinical assessment of responsiveness. Since the duration of tourniquet inflation was similar in both groups (corresponding to the similar top-up doses of vecuronium), we assume that a potential hemodynamic response to tourniquet inflation would have been similar in both groups. One patient from the $\mathrm{N}_{2} \mathrm{O} /$ desflurane group reported awareness and recall in the postoperative interviews. $^{20}$ This episode was well before the first study period and actually not related to the administration of the study gas.

Cardiovascular stability in our healthy patients anesthetized with a combination of $\mathrm{N}_{2} \mathrm{O}$ and desflurane was similar than in those anesthetized with xenon. Low concentrations of desflurane, as applied in our study, sufficient to maintain a BIS of 40 to 65 , were administered successfully in patients with inoperable coronary artery disease with a mean ejection fraction of $49 \% .31$ Despite the negative inotropic effect of desflurane, the ability of the heart to respond to increased preload was preserved in patients with a mean ejection fraction of $53 \%$ undergoing coronary surgery. ${ }^{32}$ Thus, the true clinical utility of xenon justifying its cost remains open to question. Eventually, an ongoing study in patients with poor cardiovascular function may demonstrate some advantage of xenon over conventional anesthetics or its unique neuroprotective effect ${ }^{33,34}$ detected in animal studies will be more important.

We conclude that alfentanil requirements and hemodynamic stability in healthy patients anesthetized with xenon and a MAC-equivalent combination of $\mathrm{N}_{2} \mathrm{O}$ and desflurane are similar.

\section{Acknowledgements}

We thank Rolf Lauber, Ph.D., and the analytical laboratory of the Department of Anesthesiology, University Hospital of Bern, for their analysis of alfentanil plasma concentrations. Messer Griesheim GmbH, Krefeld, Germany, generously provided the xenon gas. We also acknowledge Daniel I. Sessler, M.D., Director Outcomes Research Institute, Louisville, KY, USA for critically reviewing the manuscript.

\section{References}

1 Lachmann B, Armbruster S, Schairer W, et al. Safety and efficacy of xenon in routine use as an inhalational anaesthetic. Lancet 1990; 335: 1413-5.

2 Goto T, Saito H, Shinkai M, Nakata $\Upsilon$, Ichinose F, Morita $S$. Xenon provides faster emergence from anesthesia than does nitrous oxide-sevoflurane or nitrous oxide-isoflurane. Anesthesiology 1997; 86: 1273-8.

3 Hettrick DA, Pagel PS, Kersten JR, et al. Cardiovascular effects of xenon in isoflurane-anesthetized dogs with dilated cardiomyopathy. Anesthesiology 1998; 89: 1166-73.

4 Luttropp HH, Romner B, Perhag L, Eskilsson J, Fredriksen $S$, Werner $O$. Left ventricular performance and cerebral haemodynamics during xenon anaesthesia. A transoesophageal echocardiography and transcranial Doppler sonography study. Anaesthesia 1993; 48: 1045-9.

5 Lane GA, Nabrwold ML, Tait AR, Taylor-Busch M, Cohen PJ, Beaudoin AR. Anesthetics as teratogens: nitrous oxide is fetotoxic, xenon is not. Science 1980; 210: 899-901.

6 Rossaint R, Reyle-Hahn M, Schulte Am Esch J, et al. Multicenter randomized comparison of the efficacy and safety of xenon and isoflurane in patients undergoing elective surgery. Anesthesiology 2003; 98: 6-13.

7 Goto T, Nakata $\Upsilon$, Ishiguro $\Upsilon$, Niimi $\Upsilon$, Suwa K, Morita $S$. Minimum alveolar concentration-awake of xenon alone and in combination with isoflurane or sevoflurane. Anesthesiology 2000; 93: 1188-93.

8 Russsell IF. Comparison of wakefulness with two anaesthetic regimens. Total i.v. v. balanced anaesthesia. Br J Anaesth 1986; 58: 965-8.

9 Rampil IJ, Lockhart SH, Zwass MS, et al. Clinical characteristics of desflurane in surgical patients: minimum alveolar concentration. Anesthesiology 1991; 74: 429-33.

10 Nickalls RW, Mapleson WW. Age-related iso-MAC charts for isoflurane, sevoflurane and desflurane in man. Br J Anaesth 2003; 91: 170-4.

11 Pocock SJ. Methods of randomization. In: Pocock SJ (Ed.). Clinical Trials. A Practical Approach. Chichester: John Wiley \& Sons; 1984: 80-7.

12 Lemmens HJ, Bovill JG, Hennis PJ, Gladines MP, Burm $A G$. Alcohol consumption alters the pharmacodynamics of alfentanil. Anesthesiology 1989; 71: 669-74.

13 Raemer DB, Buschman A, Varvel JR, et al. The prospective use of population pharmacokinetics in a computer-driven infusion system for alfentanil. Anesthesiology 1990; 73: 66-72.

14 Iselin-Chaves IA, Flaishon R, Sebel PS, et al. The effect of the interaction of propofol and alfentanil on recall, loss of consciousness, and the bispectral index. Anesth Analg 1998; 87: 949-55. 
15 Ausems ME, Hug CC Jr, Stanski DR, Burm AG. Plasma concentrations of alfentanil required to supplement nitrous oxide anesthesia for general surgery. Anesthesiology 1986; 65: 362-73.

16 Luginbubl $M$, Lauber R, Feigenwinter P, Zbinden AM. Monitoring xenon in the breathing circuit with a thermal conductivity sensor. Comparison with a mass spectrometer and implications on monitoring other gases. J Clin Monit Comput 2002; 17: 23-30.

17 Kingsbury DP, Makowski GS, Stone JA. Quantitative analysis of fentanyl in pharmaceutical preparations by gas chromatography-mass spectrometry. J Anal Toxicol 1995; 19: 27-30.

18 Gan TJ, Glass PS, Windsor A, et al. Bispectral index monitoring allows faster emergence and improved recovery from propofol, alfentanil, and nitrous oxide anesthesia. BIS Utility Study Group. Anesthesiology 1997; 87: 808-15.

19 Lavigne M, Parvizi J, Beck M, Siebenrock KA, Ganz R, Leunig $M$. Anterior femoroacetabular impingement. Part I. Techniques of joint preserving surgery. Clin Orthop 2004; 61-6.

20 Luginbubl M, Schnider TW. Detection of awareness with the bispectral index: two case reports. Anesthesiology 2002; 96: 241-3.

21 Rampil IJ, Mason P, Singh H. Anesthetic potency (MAC) is independent of forebrain structures in the rat. Anesthesiology 1993; 78: 707-12.

22 Doi M, Gajraj RJ, Mantzaridis H, Kenny GN. Prediction of movement at laryngeal mask airway insertion: comparison of auditory evoked potential index, bispectral index, spectral edge frequency and median frequency. Br J Anaesth 1999; 82: 203-7.

23 Rampil IJ, Kim JS, Lenhardt R, Negishi C, Sessler DI. Bispectral EEG index during nitrous oxide administration. Anesthesiology 1998; 89: 671-7.

24 Song D, Joshi GP, White PF. Titration of volatile anesthetics using bispectral index facilitates recovery after ambulatory anesthesia. Anesthesiology 1997; 87: 842-8.

25 Goto T, Nakata V, Saito H, et al. Bispectral analysis of the electroencephalogram does not predict responsiveness to verbal command in patients emerging from xenon anaesthesia. Br J Anaesth 2000; 85: 359-67.

26 Cullen SC, Eger EI II, Cullen BF, Gregory P. Observations on the anesthetic effect of the combination of xenon and halothane. Anesthesiology 1969; 31: 305-9.

27 Nakata $\Upsilon$, Goto T, Ishiguro $\Upsilon$, et al. Minimum alveolar concentration (MAC) of xenon with sevoflurane in humans. Anesthesiology 2001; 94: 611-4.

28 Gambus PL, Gregg KM, Shafer SL. Validation of the alfentanil canonical univariate parameter as a measure of opioid effect on the electroencephalogram.
Anesthesiology 1995; 83: 747-56.

29 Nakata $\Upsilon$, Goto T, Saito H, et al. Plasma concentration of fentanyl with xenon to block somatic and hemodynamic responses to surgical incision. Anesthesiology 2000; 92: 1043-8.

30 Vuyk J, Lim T, Engbers FH, Burm AG, Vletter AA, Bovill JG. Pharmacodynamics of alfentanil as a supplement to propofol or nitrous oxide for lower abdominal surgery in female patients. Anesthesiology 1993; 78 : 1036-45.

31 Lathi KG, Vale PR, Losordo DW, et al. Gene therapy with vascular endothelial growth factor for inoperable coronary artery disease: anesthetic management and results. Anesth Analg 2001; 92: 19-25.

32 De Hert SG, Van der Linden PJ, ten Broecke PW, Vermeylen KT, Rodrigus IE, Stockman BA. Effects of desflurane and sevoflurane on length-dependent regulation of myocardial function in coronary surgery patients. Anesthesiology 2001; 95: 357-63.

33 Ma D, Wilhelm S, Maze M, Franks NP. Neuroprotective and neurotoxic properties of the 'inert' gas, xenon. Br J Anaesth 2002; 89: 739-46.

34 Ma D, Yang H, Lynch J, Franks NP, Maze M, Grocott $H P$. Xenon attenuates cardiopulmonary bypass-induced neurologic and neurocognitive dysfunction in the rat. Anesthesiology 2003; 98: 690-8. 